\title{
A minimum-error, energy-constrained neural encoder predicts an instantaneous spike-rate code
}

\author{
Erik C Johnson ${ }^{1,2,3^{*}}$, Douglas L Jones ${ }^{1,2,3,4}$, Rama Ratnam²,3,4 \\ From 24th Annual Computational Neuroscience Meeting: CNS*2015 \\ Prague, Czech Republic. 18-23 July 2015
}

An action potential (spike) is metabolically expensive to generate, and it is likely that selective pressure has been exerted on the nervous system to generate energy-efficient neural codes [1]. An additional constraint in sensory systems is that the encoding should also represent stimuli with minimal error. We postulate that this leads to a trade-off between energy expenditure and encoding error, and propose that an optimal neural code should minimize encoding error subject to a constraint on the energy expended. A first approximation of energy expenditure by a spiking neuron is $E=b+k N_{s}$, where $E$ : expended energy, $b$ : baseline rate, $k$ : cost per spike, and $N_{s}$ : the number of spikes fired. Figure $1 \mathrm{~A}$ depicts the encoding of an input signal $s(t)$ as a spike-train. Given an energy constraint $E$, the goal is to obtain the best possible reconstruction $r(t)$ of $s(t)$, with a simple low-pass filter $h(t)=A \exp (-t / \tau)$ (mimicking a postsynaptic cell membrane) such that average squared reconstruction error $e(t)=s(t)-r(t)$ (Figure 1A) is minimized. Previously we showed that minimal error encoding, subject to a spike-rate constraint, is equivalent to a non-resetting dynamic threshold spike-firing model [2] with an dynamic threshold $h(t)$ and firing level $\gamma$. Here, we show that this encoder can be interpreted as an instantaneous rate encoder with rate $i(t)=(s(t) / \tau+$ $\left.s^{\prime}(t)\right) / A$. The function closely approximates the PSTH. We tested the instantaneous rate coder by predicting: i) spike-times (Figure 1B, see raster), and reconstruction (Figure 1B, top panel), and ii) the smoothed PSTH (Figure 1C) for single-neuron data from p-type primary electrosensory neurons of a weakly-electric fish (Apteronotus leptorhynchus). For signals with little variability,

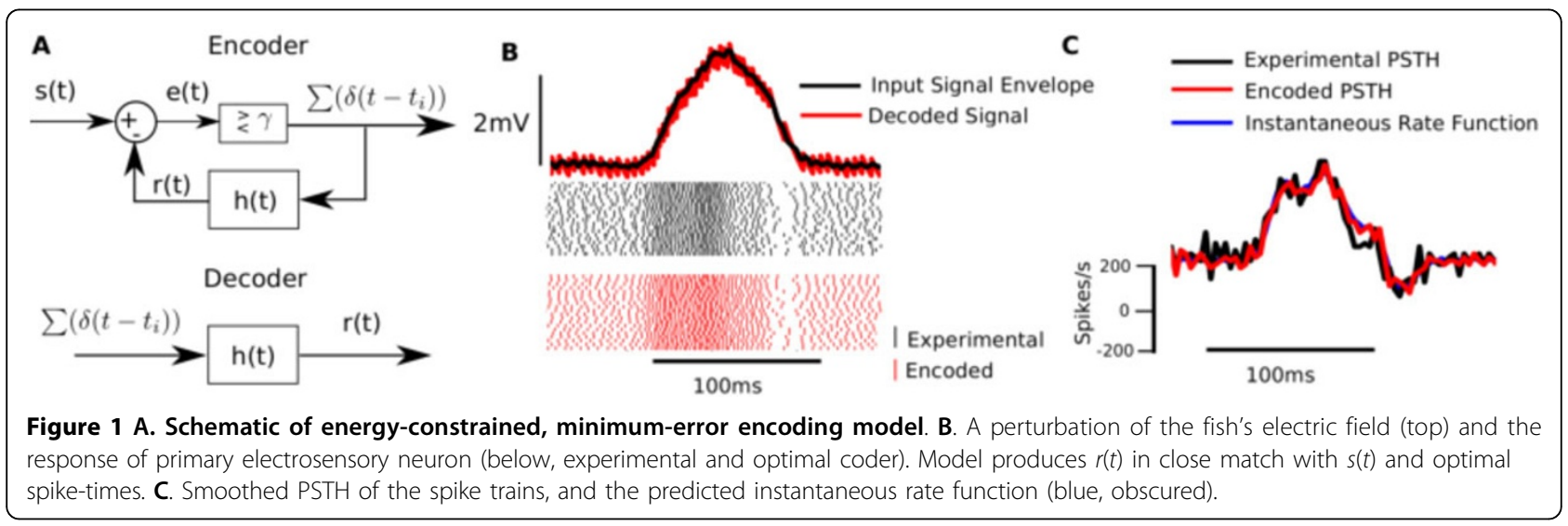

\footnotetext{
* Correspondence: ejohns24@illinois.edu

'Department of Electrical \& Computer Engineering, University of Illinois,

Urbana, IL 61801, USA

Full list of author information is available at the end of the article
} 
this predicts a rate-code of signal intensity. For signals with high variability, the spike-rate is driven by the changes in the signal (i.e., its derivative). We conclude that optimal encoder can optimally time spikes while maintaining high coding fidelity, which can be interpreted as an instantaneous rate code.

\section{Acknowledgements}

This research was supported by NSF EFRI-BSBA-0938007, NSF IGERT 0903622, the College of Engineering, UIUC, and a research grant for the Human Sixth Sense Programme at the Advanced Digital Sciences Center from Singapore's Agency for Science, Technology and Research (A*STAR). Electric fish data was collected in the laboratory of Mark E. Nelson, UIUC, through NIH R01MH49242 and NSF IBN-0078206.

\section{Authors' details}

'Department of Electrical \& Computer Engineering, University of Illinois, Urbana, IL 61801, USA. ${ }^{2}$ Beckman Institute for Advanced Science and Technology, University of Illinois, Urbana, IL, 61801, USA. ${ }^{3}$ Coordinated Science Laboratory, University of Illinois, Urbana, IL, 61801, USA. ${ }^{4}$ Advanced Digital Sciences Center, Illinois at Singapore Pte. Ltd., Singapore.

Published: 18 December 2015

\section{References}

1. Laughlin SB: Energy as a constraint on the coding and processing of sensory information. Curr Opin Neurobiol 2001, 11(4):475-480.

2. Kobayashi R, Tsubo T, Shinomoto S: Made-to-order spiking neuron model equipped with a multi-timescale adaptive threshold. Front Comput Neurosci 2009, 3:9.

doi:10.1186/1471-2202-16-S1-P201

Cite this article as: Johnson et al: A minimum-error, energy-constrained neural encoder predicts an instantaneous spike-rate code. BMC

Neuroscience 2015 16(Suppl 1):P201.

\section{Submit your next manuscript to BioMed Central} and take full advantage of:

- Convenient online submission

- Thorough peer review

- No space constraints or color figure charges

- Immediate publication on acceptance

- Inclusion in PubMed, CAS, Scopus and Google Scholar

- Research which is freely available for redistribution

Submit your manuscript at www.biomedcentral.com/submit
Ciomed Central 